\title{
Shelf-Life Study of a Vegetable-Based Juice Prepared Using a Masticating Juicer
}

Karen Edgar ${ }^{1}$, Helen Heacock ${ }^{2}$, Ken Keilbart ${ }^{3}$, Melinda Lee ${ }^{4}$

1 Lead Author, B. Tech Student, School of Health Sciences, British Columbia Institute of Technology, 3700 Willingdon Ave, Burnaby, BC, V5G 3H2

2 Supervisor, School of Health Sciences, British Columbia Institute of Technology, 3700 Willingdon Ave, Burnaby BC, V5G 3H2

3,4 Contributors, School of Health Sciences, British Columbia Institute of Technology, 3700 Willingdon

Ave, Burnaby BC, V5G 3H2

\section{Abstract}

Background

Home juicing has seen a rise in popularity because it gives people an appetizing way to get their daily intake of fresh fruits and vegetables. The roles of proper refrigeration, pasteurization, and acidification are all important in regards to determining the shelf life of a freshly made juice. As the general public may not properly understand these implications, this could become a major concern for public health officials.

Methods

A vegetable-based juice, made with carrots, celery, apples and parsley was made using a masticating juicer. Two versions of the juice were made, one original and one acidified. The $\mathrm{pH}$, total coliforms, and total bacterial levels were monitored in both versions of the juice over a fifteen-day period. $\underline{\text { Results }}$

Analyses were carried out with the two juice samples. The $\mathrm{pH}$ values of the two juices were significantly different $(\mathrm{p}=0.0000)$. No statistically significant difference was found in either the total number of aerobic bacteria or coliforms in the acidified and original juices.

The relationship between total bacterial count and $\mathrm{pH}$ in the both the acidified and neutral juices were statistically significant, $r=0.7659, p=0.0098$ and $r=0.7334, p=0.0158$, respectively. No statistically significant correlation was found between coliforms and $\mathrm{pH}$.

Conclusion

Although it was expected that the acidified juice would have had a lower levels of bacterial growth, this research project failed to show this. The total bacterial levels in the acidified juice was greater than $10^{6} \mathrm{CFU} / \mathrm{g}$ on Day 8 and the original juice was greater than $10^{6} \mathrm{CFU} / \mathrm{g}$ on Day 10 . Regardless of the $\mathrm{pH}$, the safest and lowest bacterial levels will be right when the juice is made.

Keywords: home-juicing, pH, acidity, vegetables, food safety, farmers markets, bacteria, coliforms

\section{Introduction}

The purpose of this report was to determine the shelf life of a homemade vegetable-based juice. With the current popular initiative to eat healthier, home juicing provides consumers with an enjoyable alternative to getting their daily requirements of fresh fruits and vegetables. One concern is that consumers are unaware of the risks associated with the consumption of unprocessed foods. In order to examine the plausible variables present in home juicing setups, one batch of juice was made, and then divided up, with one portion being acidified and the other left alone.

Homemade juices are generally not pasteurized; therefore the use of refrigeration to limit pathogen growth is very important. Freezing can also be done to extend the shelf life of the juice. The $\mathrm{pH}$ of the final juice product also plays a huge role in the ability for pathogens 
to grow. Maintaining the $\mathrm{pH}$ below 4.6 is especially important because the juice is a readyto-eat product, and there is no bacterial kill step between when it is made and when it is consumed.

In order to quantify the danger, this study measured the total number of aerobic bacteria and coliforms in the two different $\mathrm{pH}$ juices, which indicates the overall safety of the juice. The results of this study provide information to the general public on the acceptable shelf life of this particular juice, and possibly provide guidance to the safety of similar homemade juices.

\section{Literature Review}

As an Environmental Health student, with a background in Food Technology, the author was concerned with the public's knowledge when switching from overly processed foods to healthy foods. Processed foods are generally safer because the ingredients are manipulated in such a way to drastically increase the shelf life of the food. This can be done by reducing the water activity below 0.85 and/or decreasing the $\mathrm{pH}$ below 4.6. With healthier foods, such as homemade juices, the hurdles (the barriers that pathogens must overcome to contaminate a food) are generally not built into the foods, as they would be with processed foods, and therefore they have a higher risk of becoming contaminated. The use of refrigeration is generally the only hurdle that can be easily employed to increase the shelf life of these healthier foods, and it must be noted that refrigeration does not destroy bacteria; it only slows their growth. Therefore, over time refrigeration does not keep unpasteurized juice safe (HealthLink BC, 2010) and this can possibly lead to a foodborne illness (FBI).

Besides refrigeration, pasteurization can easily be implemented to increase the shelf life of homemade juices. Pasteurization is a thermal process where food is heated to a certain temperature that kills disease-causing microorganisms and thereby, reduces the levels of spoilage organisms (Prescott, Harley, \& Klein, 2005). To pasteurize juice, the BC Centre for
Disease Control ([BCCDC], 2013) recommends using a double-boiler to heat the juice to approximately $70^{\circ} \mathrm{C}$ while constantly stirring. Once the juice is maintained at this temperature for at least 1 minute, the juice can be poured into clean, sterilized and preheated containers then sealed with new caps.

\section{Public Health Concerns}

Home juicing can be a healthy option. There have been outbreaks in the past that have been associated with consumption of unpasteurized juice. Even though outbreaks associated with unpasteurized juice are infrequent, the risk still exists for such foodborne illnesses to occur. Both commercially prepared and home made juices have caused outbreaks. An example of a commercial outbreak occurred in October 1996, where 28 people were affected from drinking unpasteurized apple juice contaminated with the E. coli O157:H7 (Centers for Disease Control and Prevention [CDC], 1996). Outbreaks can also occur on a smallerscale. In October of 1998, Tamblyn, deGrosbois, Taylor, and Stratton (1999) reported an outbreak involving unpasteurized apple cider. Seventy gallons of apple cider was pressed at two family farms and was shared amongst family and friends. Epidemiological evidence suggested that the juice was contaminated with E. coli O157:H7 and 14 cases resulted.

Foodborne illness caused by E. coli O157:H7, Salmonella and other pathogens can cause long-term health effects to those people affected. For example, haemolytic uremic syndrome (HUS) is a result of an infection with E. coli O157:H7. This disease is characterized by kidney failure and perhaps neurological impairment (Public Health Agency of Canada [PHAC], 2012). Those people most at risk are those who are immune-compromised, very young and the elderly, and pregnant women (BCCDC, 2013). It is not recommended that these at-risk groups consume high-risk foods, such as unpasteurized juice, as their bodies are more susceptible to illness.

Other than the risk of outbreaks, there are concerns regarding to how to prepare and store freshly made juices safely to prevent 
foodborne illness (FBI). From a public health point of view the longer the juice is stored, even at refrigeration temperature, the higher the probability that pathogens in the juice will reach high enough levels, such that foodborne illness could result.

The public health concern is greater for those freshly made juices that have a $\mathrm{pH}$ greater than 4.6. The intrinsic factor of $\mathrm{pH}$ is very important in modifying the shelf life of various foods. Generally, pathogens do not grow, or grow at a much slower rate, at a $\mathrm{pH}$ of less than 4.6 (US Food and Drug Administration [US FDA], 2013). Maintaining a $\mathrm{pH}$ of less than 4.6 is very important for ready-to-eat (RTE) foods, such as home made juice, since there is no kill step between when the food is made and when it is consumed. Freshly prepared unpasteurized juice, especially those made of mostly vegetables, generally have a $\mathrm{pH}$ greater than 4.6 and therefore should be consumed right after they are made.

\section{Microbiological Guidelines for RTE Foods}

The use of plate count agar (PCA) is one of the most common methods to determine the microbiological safety of foods (Food Standards, 2001). Based on the guidelines from Food Standards (2001), PCA is not applicable for foods such as fresh fruits and vegetables, as they are expected to have an inherent high plate count because of their normal flora. They also suggest not directly basing the results on PCA alone, since PCA counts the total bacterial load on the food. When the PCA results show the food product to be unsatisfactory, Gilbert et al. (2000) suggest trying to identify the predominant microorganisms present in the food to get a more useful interpretation of the microorganisms that are present, thereby determining the overall quality of the food.

Based on the guidelines produced by Gilbert et al. (2000), freshly made juice, is not one of the ready-to-eat foods listed. They suggest using your own judgement to assess what food category it best fits in, based on the type of product, the processing it has received, and the potential for microbial growth during storage. Given these guidelines, fresh juice seems to match closely with prepared mixed salads, which is a category 4 ready-to-eat food, since salads also require minimal processing and have no cooking steps. According to Gilbert et al. (2000) if the aerobic colony count $\left(30^{\circ} \mathrm{C}\right.$ for 48 hours) of the category 4 food has a microbiological quality of less than $10^{6} \mathrm{CFU} / \mathrm{g}$, the food product is considered to be satisfactory.

\section{Home Juicing}

\section{Popularity of Home Juicing}

The current trend is working towards increasing the overall health of the population. Thanks to this movement, people are making more informed decisions about the foods they are consuming, such as eating more fresh fruits and vegetables. Home juicing is a tasty way that people can consume part of their daily intake of fresh fruits and vegetables rather than drinking the overly sweetened fruit juices or forcing themselves to eat raw vegetables.

According to the NPD Group, Inc. (as cited in Sanderson, 2013), a market research company, the global sales of juicers jumped 31\% between 2011 and 2012. Although it cannot be confirmed that there was also an increase in the production of juices, the growth does indicate a large population of people getting into juicing, and thus the need for understanding how to prepare fresh juice and store it properly could become a major public health concern.

\section{Microorganisms Commonly Associated with Fresh Fruits and Vegetables}

The microorganisms commonly associated with fresh juice are generally the same microorganisms found in fresh produce. These microorganisms are coupled with the various processes required to get fresh fruits and vegetables from the farm to your table. The bacterial load of fresh produce can vary greatly as there are a number of factors that can cause contamination of the raw produce. On the farm some of those factors include the use of: manure as fertilizer, contaminated irrigation water, and contaminated harvesting equipment; as well as, poor hygiene of workers in the field, and the presence of wild animals (Matthews, 2006). Contamination can also occur after the produce 
has left the farm, such as during storage, processing, distribution, retail display, and/or home preparation (Gorny, 2006). Microorganisms can also be found naturally on the produce itself.

The presence, numbers and source of microorganisms on the produce are dependent on, but are not limited to, the type of produce, the weather conditions and the agronomic practices (Matthews, 2006). Splittstoesser (as cited in Burnett, \& Beuchat, 2001) states that Gram-negative bacteria are more frequently associated with vegetables, whereas yeasts and moulds are more commonly found on raw fruits. Yeasts and mould are generally found on fruits because they can survive in acidic conditions, whereas bacteria cannot.

\section{Preparation}

Prior to actually juicing, fresh fruits and vegetables need to be selected. The BCCDC (2005) recommends selecting produce that does not appear dirty, as they are harder to clean. They also suggest discarding any outer leaves from any leafy vegetables, as these are potentially the most heavily contaminated. For home juicing, the fruits and vegetables need to be prepared before they should be put into the juicer. They need to be properly cleaned to reduce the overall bacterial load. HealthLink BC (2007) has provided recommendations on how to prevent illness by making fresh fruits and vegetables safe to eat. They suggest to first wash your hands with soap and water, and then wash the produce with dilute soap solution followed by a rinse in clean running water (HealthLink BC, 2007). Finally, remove or cut off any damaged or bruised sections as these areas generally support the growth of harmful bacteria. To begin juicing, the fruits and vegetables have to be cut to a size small enough to be to be put into the opening of the juicer, and then it's time to start juicing.

\section{Juicing Process}

There are two basic types of juicers on the market: the masticating and the centrifugal juicer. With the masticating juicer, the fruits and vegetables are squeezed and crushed, then forced though a fine stainless steel strainer (Crocker, 2008). This yields a juice with a high nutritional content. Generally, this type of juicer costs more than a centrifugal juicer.

The centrifugal juicer is the most popular type of juicer (Huffpost Taste, 2013). The fruits and vegetables are shredded by a spinning basket; the spinning creates heat and draws in oxygen, which reduces the nutritional quality of the juice (Crocker, 2008). Those who are not as concerned about the nutritional benefits of juicing, generally choose this type because of its lower price tag (Huffpost Taste, 2013).

\section{Microbial Analysis of Unpasteurized Juice}

Previous research has looked at the microbial quality and safety of unpasteurized juices. The research studies were completed in countries in the Eastern Hemisphere such as Qatar, India and Nigeria. Although the climate and the way of living are different than what is found in Canada, the methods and findings of the research should be at least be considered as a basis for further research.

Research carried out by Al-Jedah and Robinson (2002) investigated both the nutritional value and the microbiological safety of a variety of different freshly made fruit juices sold at retail outlets in Doha, Qatar. Juice varieties tested included apple, avocado, banana and many others. They were testing for total colony count, coliforms, E. coli, S. aureus, P. aeurginosa, E. faecalis, as well as, yeasts and moulds. The results indicated that the microbiological quality of all the juices tested were outside the Gulf Standards for fruit juices. This study focused on fruit juices purchased from retail outlets, the researchers did not prepare the juices themselves. Also the juices were examined after being stored at $4^{\circ} \mathrm{C}$ for two hours. They did not bother looking at the change of nutritional value or microbiological safety over a period of time.

A research paper by Mahale, Khade, and Vaidya (2008), analyzed three different juices (sugarcane, lime and carrot) sold by street vendors in Mumbai, India. For each juice, they tested the $\mathrm{pH}$ and performed microbiological analysis. The researchers performed a total 
aerobic plate count and completed further testing for specific organisms such as coliforms, faecal coliforms, Vibrio, Shigella, Salmonella, and Staphylococcus aureus. The results of the study showed higher microbial counts in the higher $\mathrm{pH}$ juices (carrot: 6.2, sugarcane: 5.4), compared to the lower $\mathrm{pH}$ juice (lime: 2.3). Given these results, the researchers suggested the urgent need of government participation to develop intervention programs to improve the quality of these fresh juices. The fact that the researchers compared $\mathrm{pH}$ to the microbial growth of the different juices is very interesting, although they also did not look at the changes in $\mathrm{pH}$ or microbiological quality over time.

A third research paper, by Ukwo, Ndaeyo, and Udoh (2011), looked at the microbiological quality and safety of fresh juices sold at road side vendors in Uyo Metropolis in Nigeria. In this study, the varieties of fresh juices that were tested were lime, lemon, pineapple, orange, carrot and garlic juices. Analyses of these juices were completed after one hour of obtaining the samples. The organisms that were tested for included total viable count, total coliforms, faecal coliforms, $S$. aureus, Salmonella and Vibrio spp. The results of this study found a significantly large number of pathogenic microorganisms in the juices. The juices with a near neutral $\mathrm{pH}$, the carrot and garlic juices, favoured the growth of the microorganisms compared to the more acidic juices.

\section{$\underline{\text { Research Question }}$}

Given the aforementioned studies, it seems $\mathrm{pH}$ has an effect on the microbiological quality of freshly made juices, particularly when a neutral $\mathrm{pH}$ juice is compared to an acidic $\mathrm{pH}$ juice. This can become a concern for Public Health Inspectors, as improper preparation and storage of unpasteurized juices has been associated with outbreaks in the past. Previous studies have sampled freshly-made juices and analyzed them for nutritional value and microbiological safety. The researchers did not make their own juice and they did not analyze the $\mathrm{pH}$ and the microbiological quality as a factor of time. Thus, the purpose of this study is to determine the shelf life of a home made vegetable-based juice. Using plate count agar (PCA) and violet red bile agar (VRBA), the microbiological quality, and the $\mathrm{pH}$ of the juices were each analyzed on five different days, over a 15 day period, while being stored at $4^{\circ} \mathrm{C}$.

\section{Methods}

\section{Description of Standard Methods}

\section{Peptone Blanks}

As the initial load of microorganisms in both the produce and juice is unknown, the dilution blanks needed to be made, from $10^{-1}$ to $10^{-9}$.

\section{PCA}

Plate count agar (PCA) is used to determine the total viable bacterial count, and is commonly used to determine the sanitary quality of foods (Zimbro, Power, Miller, Wilson, \& Johnson, 2009).

\section{VRBA}

Total coliforms are bacteria that are naturally found in the environment and they are generally harmless, but if found in RTE foods it can indicate poor handling practices (BC Public Health Microbiology and Reference Laboratory, 2013). Violet Red Bile Agar (VRBA) is one method for enumerating total coliforms in foods and dairy products (Zimbro et al., 2009).

pH

The Corning Model $125 \mathrm{pH}$ meter was used to measure the $\mathrm{pH}$ of the juices.

\section{Reliability and Validity of Measures}

For measuring the $\mathrm{pH}$, Cheng and Zhu (2005) recommend calibrating the $\mathrm{pH}$ meter every 2-3 hours. By calibrating the $\mathrm{pH}$ meter this ensures both valid and reliable results. For PCA and VRBA, negative controls were completed each day that plating of the juice sample was completed. The positive controls were only done on the first day of plating. The negative controls were done to ensure proper sterilization of the media, whereas the positive controls were completed to ensure the media is working properly. The manufacturers of the media 
complete Certificates of Analysis for each lot produced, to ensure the media meets their high quality standards.

\section{Inclusion and Exclusion Criteria}

The inclusion criteria include the Carrot Apple recipe from Crocker (2008). The acidified version of the juice was the original juice recipe only with the addition of lemon juice. The juice was produced with a masticating juicer. Only aerobic bacteria and coliforms will be enumerated.

The exclusion criteria include all other recipes used for home juicing that use a masticating juicer and all other microorganisms other than aerobic bacteria and coliforms.

\section{Results}

\section{Description of the Data}

The bacterial counts from PCA and VRBA are discrete numerical data, since colonies can only be whole numbers. The $\mathrm{pH}$ measurements are continuous numerical data, since the $\mathrm{pH}$ meter is able to provide readings to two decimal places.

\section{Descriptive Statistics}

Juice samples were taken on Days 1, 3, 8, 10 and 15. On these days, one sample of the acidified and one sample of the original juice were analyzed. Those sampling days were selected mainly due to the accessibility to the microbiology lab. Of the 5 testing days, Day 10 was selected for analysis because the juices no longer looked or smelled appealing and the bacterial and coliform counts were quite high.

On Day 10, the mean $\mathrm{pH}$ of the acidified and the original juice was 4.49 and 5.08 , respectively. The mean total bacterial counts of the two juices are also shown above in Table 1, along with the median, mode, standard deviation. The total bacterial count of the original juice was 4,965,000 CFU/mL of juice, whereas the acidified juice was 2,525,000 $\mathrm{CFU} / \mathrm{mL}$.

\section{$\underline{\text { Inferential Statistics }}$}

The inferential statistics completed for this study were the t-test and correlation/regression analysis.

\section{$\underline{\text { Statistical Packages }}$}

The statistical packages used were Excel (Microsoft, 2010) and NCSS (Hintze, 2013). The inferential stats were analyzed with NCSS.

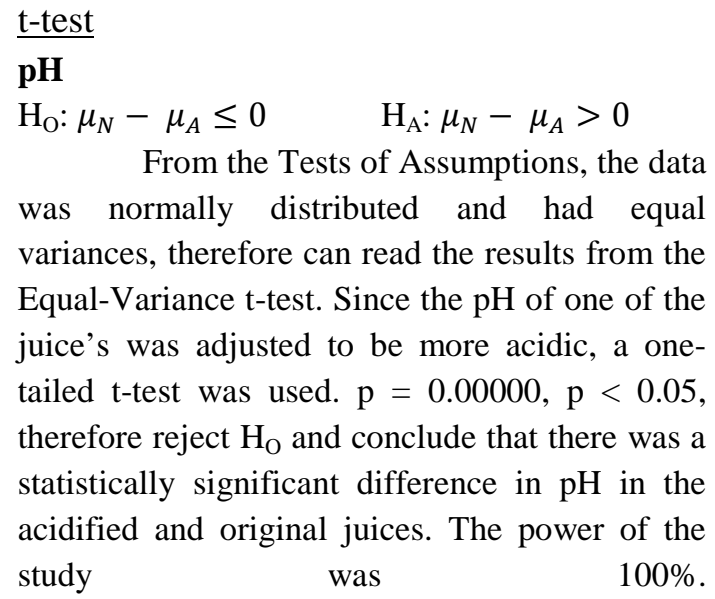

Table 1. Descriptive statistics for acidified and original juices on Day 10

\begin{tabular}{|c|c|c|c|c|c|c|}
\hline & pH acidified & pHoriginal & PCA acidified & PCA original & VRBA acidified & VRBA originol \\
\hline Mean & 4.49 & 5.08 & 2525000 & 4965000 & 1180000 & 2730000 \\
\hline Median & 4.49 & 5.08 & 2525000 & 4965000 & 1180000 & 2730000 \\
\hline Mode & $\# N / A$ & $\# \mathrm{~N} / \mathrm{A}$ & $\# N / A$ & $\# N / A$ & $\# \mathrm{~N} / \mathrm{A}$ & $\# N / A$ \\
\hline Standard Deviation & 0.03 & 0.16 & 671751 & 615183 & 1301076 & 3210265 \\
\hline Range & 0.04 & 0.23 & 950000 & 870000 & 1840000 & 4540000 \\
\hline Minimum & 4.47 & 4.96 & 2050000 & 4530000 & 260000 & 460000 \\
\hline Maximum & 4.51 & 5.19 & 3000000 & 5400000 & 2100000 & 5000000 \\
\hline Count & 2 & 2 & 2 & 2 & 2 & 2 \\
\hline
\end{tabular}




\section{PCA}

$$
\mathrm{H}_{\mathrm{O}}: \mu_{N}-\mu_{A}=0 \quad \mathrm{H}_{\mathrm{A}}: \mu_{N}-\mu_{A} \neq 0
$$

A two-tailed t-test was used because the direction of the difference in PCA between the acidified and original juice was unknown. From the Tests of Assumptions, the normality and equal variances were both accepted, therefore must read the Equal-Variance t-test. $\mathrm{p}=0.89292$, $\mathrm{p}>0.05$, therefore cannot reject $\mathrm{H}_{\mathrm{O}}$ and must conclude that there is not a statistically significant difference in the total number of viable aerobic bacteria in the acidified and original juices. The power was approximately $5 \%$, which is much less than the ideal value of $80 \%$. The power could be improved by increasing the sample size.

\section{VRBA}

$\mathrm{H}_{\mathrm{O}}: \mu_{N}-\mu_{A}=0 \quad \mathrm{H}_{\mathrm{A}}: \mu_{N}-\mu_{A} \neq 0$

A two-tailed t-test is used because the direction of the difference between the acidified and original juice is not known. From the Tests of Assumptions, some of the normality tests and one of the equal variance tests were rejected, therefore must read the Mann-Whitney U test. $\mathrm{p}=$ 0.762282 (with correction), $\mathrm{p}>0.05$, therefore cannot reject $\mathrm{H}_{\mathrm{O}}$ and must conclude that there is not a statistically significant difference in the number of coliforms that were detected in the acidified and the original juices. The power is approximately $5 \%$, therefore there is a high probability that these results do not reflect truth.

\section{$\underline{\text { Regression and Correlation }}$}

\section{PCA and Acidified Juice}

The correlational coefficient is 0.7659 , therefore there is very good to excellent relationship between $\mathrm{pH}$ and PCA in the acidified juice. The equation of the line is: PCA $=11,125,174.63(\mathrm{pH})-48,678,709.63$.

\section{t-tests}

$\mathrm{H}_{\mathrm{O}}$ : slope $=0$

$\mathrm{H}_{\mathrm{A}}$ : slope $\neq 0$

$\mathrm{p}=0.0098, \mathrm{p}<0.05$, therefore do reject $\mathrm{H}_{\mathrm{O}}$. The slope is significantly different from zero, so when $\mathrm{pH}$ increases so too does the total bacterial count.
$\mathrm{H}_{\mathrm{O}}:$ intercept $=0$

$\mathrm{H}_{\mathrm{A}}$ : intercept $\neq 0$

$\mathrm{p}=0.0112, \mathrm{p}<0.05$, therefore do reject $\mathrm{H}_{\mathrm{O}}$. The intercept is significantly different from zero.

Since the p-values for both tests are close to 0.01 , there is a slight chance of an alpha error. Decreasing the acceptable p-value from 0.05 to 0.01 can reduce the possibility of this error. The power was approximately $82 \%$ for both t-tests, therefore there is a good chance that the results reflect truth.

\section{PCA and Original Juice}

The correlation coefficient is 0.7334 , which indicates a moderate to good relationship between $\mathrm{pH}$ and PCA of the original juice. The equation of the line is PCA $=7,800,245.47(\mathrm{pH})$ $-36,645,991.50$.

t-tests

$\mathrm{H}_{\mathrm{O}}$ : slope $=0$

$\mathrm{H}_{\mathrm{A}}$ : slope $\neq 0$

$\mathrm{p}=0.0158, \mathrm{p}<0.05$, therefore do reject $\mathrm{H}_{\mathrm{O}}$. The slope is significantly different from zero. Similar to the acidified juice, as the $\mathrm{pH}$ value increases, so does the total bacterial count.

$\mathrm{H}_{\mathrm{O}}:$ intercept $=0$

$\mathrm{H}_{\mathrm{A}}:$ intercept $\neq 0$

$\mathrm{p}=0.0184, \mathrm{p}<0.05$, therefore do reject $\mathrm{H}_{\mathrm{O}}$. The intercept of the line is significantly different from zero.

Since the p-values for the slope and the intercept are between 0.05 and 0.01 , there is a potential alpha error. Decreasing the acceptable alpha from 0.05 to 0.01 can prevent this type of error. The power is approximately $75 \%$ for both tests. Although the power value is less than $80 \%$, there is still a good chance that the results reflect truth.

\section{VRBA and Acidified Juice}

The correlational coefficient is 0.5075 , therefore there is moderate to good relationship between $\mathrm{pH}$ and VRBA in the acidified juice. The equation of the line is: VRBA = 4,251,746.34 (pH) -18,497,096.29. 
$\underline{\text { t-tests }}$

$\mathrm{H}_{\mathrm{O}}$ : slope $=0$

$\mathrm{H}_{\mathrm{A}}$ : slope $\neq 0$

$\mathrm{p}=0.1343, \mathrm{p}>0.05$, therefore do not reject $\mathrm{H}_{\mathrm{O}}$.

The slope is not significantly different than zero.

$\mathrm{H}_{\mathrm{O}}:$ intercept $=0$

$\mathrm{H}_{\mathrm{A}}$ : intercept $\neq 0$

$\mathrm{p}=0.1455, \mathrm{p}>0.05$, therefore do not reject $\mathrm{H}_{\mathrm{O}}$. The intercept is not significantly different than zero.

The power is approximately $30 \%$ for both intercept and slope. Ideally, the power should be $80 \%$ or greater, this can be achieved by increasing the sample size.

\section{VRBA and Original Juice}

The correlational coefficient is 0.2998 , therefore there is a fair relationship between $\mathrm{pH}$ and VRBA in the acidified juice. The equation of the line is: VRBA $=2,979,909.37(\mathrm{pH})-$ 13,786,580.06.

$\underline{\text { t-tests }}$

$\mathrm{H}_{\mathrm{O}}$ : slope $=0$

$\mathrm{H}_{\mathrm{A}}$ : slope $\neq 0$

$\mathrm{p}=0.400, \mathrm{p}>0.05$, therefore do not reject $\mathrm{H}_{\mathrm{O}}$. The slope is not significantly different than zero.

$\mathrm{H}_{\mathrm{O}}:$ intercept $=0$

$\mathrm{H}_{\mathrm{A}}:$ intercept $\neq 0$

$\mathrm{p}=0.4217, \mathrm{p}>0.05$, therefore do not reject $\mathrm{H}_{\mathrm{O}}$. The intercept is not significantly different than zero.

The power is around $12 \%$ for both the slope and the intercept. More samples need to be tested in order to increase the power of the study.

\section{Discussion}

No significant difference was found between the total aerobic bacterial count between the two different $\mathrm{pH}$ juices. Based on these results, the $\mathrm{pH}$ of the juice had little to no effect on limiting the growth of aerobic bacteria in the two juice samples. Also, the $\mathrm{pH}$ did not have a noticeable effect on the number of total coliforms that were able to grow in the two juices. The juice with a $\mathrm{pH}$ less than 4.5 was expected to have a lower bacterial count because the environmental conditions should have been less favourable for bacterial growth, but the results did not show this. One possible explanation could be due to the small sample size. The overall power values for these two tests were quite low and this could be improved by having more samples. By having a power greater than $80 \%$ gives a higher probability of the results actually represent the truth.

The number of total coliforms was not strongly correlated to the $\mathrm{pH}$ in either of the acidified or original juice samples; therefore an equation cannot be utilized to approximate the number of coliforms present in the juice. However, a strong correlation was found between the aerobic bacteria and the $\mathrm{pH}$ for the acidified and original juices. Using the equations from the Linear Regression Reports, the amount of aerobic bacteria could be calculated based on the $\mathrm{pH}$ values for both the acidified and the original juices.

When observing the results for the coliforms, the slope was not significantly different from zero. Therefore, knowing whether the total coliforms will increase as the $\mathrm{pH}$ increases cannot be determined. Yet for the aerobic bacteria, the slope was significantly different from zero, therefore as the $\mathrm{pH}$ increases, the bacterial count also increases. There is a high probability that these findings for the aerobic bacteria reflect truth due to the power values being close to $80 \%$.

Given the previous research of Al-Jedah and Robinson (2002), Mahale, Khade, and Vaidya (2008), and Ukwo, Ndaeyo, Udoh (2011) it would have been expected that the acidified juice would have had lower levels of bacterial growth than the original juice, but the findings of this research failed to show this. The acidified juice had greater than $10^{6} \mathrm{CFU} / \mathrm{g}$ of aerobic on Days 8, 10 and 15, whereas the original juice had an aerobic colony count of greater than $10^{6}$ $\mathrm{CFU} / \mathrm{g}$ only on Day 10 . On these days the juice was considered unsatisfactory according to Gilbert et al. (2000). Also, by Day 10 the overall 
odour and appearance of the juice had drastically deteriorated. Based on these results, it seems that consuming juice immediately after it has been prepared, regardless of the $\mathrm{pH}$, provides the lowest and safest level of bacteria.

Home-juicing may not seem like a topic that EHOs may be directly involved in, but it is clear that, in some circumstances, EHOs may need to educate the public and/or temporary market operators and the managers as to the risks associated with homemade unpasteurized juices.

Since the current trend is for people to eat healthier, people are more likely to increase their daily intake of fresh fruits and vegetables. One way of doing this is by using a juicer. If a high occurrence of FBI is being reported to the local health authority, EHOs may be a vital resource to educate the public on the importance of safe juicing practices.

If a food vendor has gained approval from an EHO, they may sell unpasteurized juice at a temporary food market. The BCCDC (2014) states that vendors of higher risk foods, which includes fruit and vegetable juices, must prepare their food in an approved commercial kitchen, obtain a letter of confirmation or a Permit to Operate from the Health Authority, complete FoodSafe Level 1, and maintain the temperature of the food at $4^{\circ} \mathrm{C}$ or less, from the point of packaging to the point of sale to the consumer.

\section{Recommendations and Conclusions}

Overall, given the findings above, it could not be determined when the homemade juice was no longer safe to consume. Even though it was expected that the acidified juice would have had a longer shelf life, this was not the case. There was no difference found in the amount of aerobic bacteria or the number of coliforms between the acidified and original vegetable-based juices.

The bacteria analyzed for this project, aerobic bacteria and total coliforms, are not directly associated with foodborne illness. The aerobic bacteria only give an indication as to the microbiological quality of the food, since not all bacteria are harmful. Coliforms are used as an indicator organism; if they are present in a food product, there is a high probability that pathogenic organisms may also be present.

Even when refrigerated, any bacteria present in the juice can proliferate and when, and if, the juice it consumed the bacteria could possibly cause illness. Based on the above results, the bacterial levels in the juice increase over time, and thus it can be taken with a fair degree of certainty, that the sooner the juice is consumed the safer it will likely be. Yet, more research is needed to provide the public with a better indication as to the shelf life of homemade juices.

\section{Limitations}

There were quite a few limitations that prevented this research project from being more informative. For this project, only two batches of juices were prepared. Also, the sample size should have been greater than 30 , as this will increase the chance of having normally distributed data. Furthermore, by having more samples, this should increase the power of all the t-tests that were completed. By having a higher power, the obtained results would be more likely to reflect truth.

Due to unforeseen circumstances, the two batches were completed one month apart. This is not a substantial limitation since the bacterial load on fresh produce varies considerably due to a number of different factors, such as the farming practices, as well as during storage. Although, to reduce the effects of confounders, it would have been beneficial to complete the two batches with the same produce from the same grocery store.

For the microbiology portion of the project, the juice sampling days were arranged such that the researcher could easily gain access into the lab. Overall, the sampling schedule should not have much effect on the results of this research project. During the plating of the juice sample, each sample was plated on the PCA and the VRBA media. Ideally, the plates should have been made in duplicate, but due to monetary and time constraints this was not feasible. By doing duplicates, this provides an opportunity to see if there are any outliers. 
Finally, due to the limited budget, only total bacteria and coliforms were analyzed in the juices. Total bacteria do not indicate food safety; they only indicate the microbial quality. Coliforms are used as an indicator organism therefore their presence doesn't necessarily indicate that the juice is unsafe.

\section{Future Research}

In the future, the following could be done to increase the overall knowledge in regards to the safety of homemade vegetablebased juices. Having the ability to enumerate pathogenic microorganisms in the juice samples would give a much better indication as to the overall level of safety of the juice. For instance, the use of other media and methods that are specific for pathogenic bacteria, such as E. coli, S. aureus, and Salmonella, might provide more insight into this subject. Also, by increasing the overall number of samples and by doing duplicate microbiology plates, studies could increase the reliability of their findings, and thus have better predictability.

Having information on the appearance, odour, and colour would also be interesting to take into consideration. Furthermore, taste and mouth feel would be important characteristics to consider; however, ethical considerations would need to be taken into account, because there is the potential that the people could get sick.

\section{Acknowledgements}

I would like to thank those individuals who helped and supported me throughout the process of completing this project. Firstly, I would like to thank Helen Heacock, Faculty, Environmental Health Technology Department, for her support throughout this entire project. She assisted me with analyzing the data and proofreading the written report.

I would also like to thank the following staff members of the Food Technology Department. Ken Keilbart, Assistant Instructor, for taking the time to discuss the methodology for my study and Melinda Lee, Lab Technician, for providing me with access to the microbiology lab.
Finally, I would like to thank my family and friends for their support and patience as I have spent endless hours working on this project.

\section{Competing Interest}

The authors declare that they have no competing interests.

\section{References}

Al-Jedah, J.H., \& Robinson, R. K. (2002). Nutritional value and microbiological safety of fresh fruit juices sold through retail outlets in Qatar. Pakistan Journal of Nutrition, 1(2), 79-81. Retrieved from http://scialert.net/qredirect.php?doi=pjn.2 $\underline{002.79 .81 \& \text { linkid=pdf }}$

BC Centre for Disease Control. (2005). Food safety bulletin: Reducing potential risks of foodborne illness from fresh fruits and vegetables. Retrieved from http://www.bccdc.ca/NR/rdonlyres/E6AA D291-DF5C-4367-87B0EC655FC7F8D6/0/Reducing_Risks_of_F BI_FreshFruitVeg.pdf

BC Centre for Disease Control. (2013). Food safety notes: Don't drink it raw- how to pasteurize juice and cider safely.

Retrieved from http://www.bccdc.ca/NR/rdonlyres/08C05 6CF-B2B2-4CBD-A3065E452C416602/0/pasteurizejuiceandcider safely.pdf

BC Centre for Disease Control. (2014). Temporary food markets: Guideline for the sale of foods at temporary food markets. Retrieved from http://www.bccdc.ca/NR/rdonlyres/8084E EC3-3010-4908-876E37BF359A939D/0/GuidelinesSaleofFood satTemporaryFoodMarkets2012FINAL.p $\underline{\mathrm{df}}$

BC Public Health Microbiology and Reference Laboratory. (2013). Food quality check program: Microbiology recommendations and sampling schedule-2014. Retrieved from http://www.bccdc.ca/NR/rdonlyres/5E3C E5A9-EF67-41DC-9644- 
81E8E814B931/0/FoodQualityMicroRec

ommendationsnoschedule.pdf

Burnett, S.L. \& Beuchat, L.R. (2001). Foodborne pathogens: Human pathogens associated with raw produce and unpasteurized juices, and difficulties in decontamination. Journal of Industrial Microbiology and Biotechnology, 27, 104-110. Retrieved from http://download.springer.com.ezproxy.libr ary.ubc.ca/static/pdf/14/art\%253A10.103 8\%252Fsj.jim.7000199.pdf?auth66=1382 163044 bf0b4b9745f8f2711433da9a9e34 fe2f\&ext=.pdf

Centers for Disease Control and Prevention. (1996). Outbreak of Escherichia coli O157:H7 infections associated with drinking unpasteurized commercial apple juice-British Columbia, California, Colorado, and Washington, October 1996. Retrieved from

http://www.cdc.gov/mmwr/preview/mmw rhtml/00044358.htm

Cheng, K.L. \& Zhu, D. (2005). On calibration of $\mathrm{pH}$ meters. Sensors, 5. Retrieved from https://www.google.ca/search?q=frequenc $\mathrm{y}+\mathrm{of}+$ calibration $+\mathrm{of}+\mathrm{ph}+$ meter\&ie $=$ utf8\&oe=utf-8\&rls=org.mozilla:enUS:official\&client=firefoxa\&channel=fflb\&gws rd=cr\&ei=xteGUp 6SNcTmiwKVjoCYBQ

Crocker, P. (2008). The juicing bible. Toronto, ON: Robert Rose Inc.

Food Standards. (2001). Guidelines for microbiological examination of ready-toeat foods. Retrieved from http://www.foodstandards.gov.au/publicat ions/pages/guidelinesformicrobi1306.aspx

Gilbert, R.J., de Louvois, J., Donovan, T., Little, C., Nye, K., Ribeiro, C.D.,... Bolton, F.J. (2000). Guidelines for the microbiological quality of some ready-to-eat foods samples at the point of sale. Communicable Disease and Public Health, 3(3), 163-167. Retrieved from http://webarchive.nationalarchives.gov.uk /+/http://www.hpa.org.uk/cdph/issues/CD PHVol3/no3/guides_micro.pdf
Gorny, J. (2006). Microbial contamination of fresh fruits and vegetables. In G.M. Sapers, J.R. Gorny \& A. E. Yousef (Eds.), Microbiology of fruits and vegetables (pp. 3-32). Boca Raton, FL; Taylor Francis Group.

HealthLink BC. (2007). Food safety for fresh fruits and vegetables. Retrieved from http://www.healthlinkbc.ca/healthfiles/hfi le59b.stm

HealthLink BC. (2010). Unpasteurized fruit juices and ciders: A potential health risk. Retrieved from http://www.healthlinkbc.ca/healthfiles/hfi le72.stm

Hintze, J. (2013). NCSS 9. NCSS, LLC. Kaysville, Utah.

Huffpost Taste. (2013). Juicer types: The difference between cold press juicers vs. centrifugal juice extractors. Retrieved from

http://www.huffingtonpost.com/2013/02/ 08/juicer-types-coldpress_n_2618000.html

Mahale, D.P., Khade, R.G., \& Vaidya, V.K. (2008). Microbiological analysis of street vended fruit juices from Mumbai City, India. Internet Journal of Food Safety, (10), 31-34. Retrieved from http://www.internetjfs.org/articles/ijfsv10 $\underline{-5 . p d f}$

Matthews, K.R. (2006). Microorganisms associated with fruits and vegetables. In K.R. Matthews (Eds.), Microbiology of fresh produce (1-19). Washington, DC: ASM Press.

Microsoft. (2010). Microsoft Excel for Mac (Version 14.3.7). Microsoft Corporation.

Public Health Agency of Canada. (2012). Public health notice: E. coli O157 illness related to beef. Retrieved from http://www.phacaspc.gc.ca/fs-sa/phn-asp/ecoli-1012eng.php

Prescott, L.M., Harley, J.P., \& Klein, D.A. (2005). Microbiology (6th ed.). New York, NY: McGraw-Hill.

Sanderson, V. (2013, Oct 4). Juicing trend inspires new muscle to do the job. The Star. Retrieved from 
http://www.thestar.com/life/homes/2013/ 10/04/juicing_trend_inspires_new_muscl e to do the job.html

Tamblyn, S., deGrosbois, J., Taylor, D., \& Stratton J. (1999). An outbreak of Escherichia coli 0157:H7 infection associated with unpasteurized noncommercial, custom-pressed apple cider-Ontario, 1998. Canada Communicable Disease Report, 25. Retrieved from http://www.collectionscanada.gc.ca/webar chives/20071225013919/http://www.phac -aspc.gc.ca/publicat/ccdrrmtc/99vol25/dr2513ea.html

Ukwo, S.P., Ndaeyo, N.U., \& Udoh, E.J. (2011). Microbiological quality and safety evaluation of fresh juices and edible ice sold in Uyo Metropolis, South-South, Nigeria. Internet Journal of Food Safety, 13, 374-378. Retrieved from http://www.internetjfs.org/articles/ijfsv13 -59.pdf

US Food and Drug Administration. (2013). Factors that influence microbial growth. In Evaluation and definition of potentially hazardous foods (chapter 3). Retrieved from http://www.fda.gov/Food/FoodScienceRe search/SafePracticesforFoodProcesses/uc $\underline{\text { m094145.htm }}$

Zimbro, M.J., Power, D.A., Miller, S.M., Wilson, G.E., \& Johnson, J.A. (Eds.). (2009). Difco \& BBL manual: manual of microbiological culture media (2nd ed.). Sparks, MD: Becton, Dickinson and Company. 